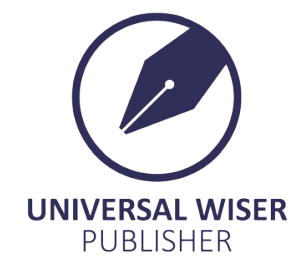

\title{
Inclusion Complexation of Benzanilide and Fast Violet B with $\beta$-cyclodextrin-A Theoretical Approach
}

\author{
A. Antony Muthu Prabhu \\ Department of PG Chemistry, Aditanar College of Arts and Science, Virapandianpatnam, Tiruchendur 628 216, Tamilnadu, India \\ Email: antonyphdchem@yahoo.com
}

\begin{abstract}
The theoretical investigation of inclusion complexation of amide-imidol tautomer of two guest molecules benzanilide (BA) and fast violet B (FVB) with $\beta$-cyclodextrin ( $\beta-C D)$ using DFT B3LYP 3-21G method in the gas phase. Benzanilide has no substitution in the basic skeleton and the other selected compound substituted with three groups such as $-\mathrm{NH}_{2},-\mathrm{CH}_{3}$ and $-\mathrm{OCH}_{3}$ group in the same aromatic ring. The tautomer of two selected compounds was formed the stable inclusion complexes with the $\beta-\mathrm{CD}$ supramolecule. The theoretically calculated complexation energy was observed the negative value for all the inclusion complexes. This method was applicable to determine the structural assignment of the inclusion complexes between BA, FVB and $\beta$-CD.

Keywords: benzanilide, fast violet B, inclusion complexes, DFT B3LYP 3-21G method
\end{abstract}

\section{Introduction}

Benzanilide generally was prepared by treating benzoic acid with aniline using a very simple method. The amideimidol tautomer was formed through photoinduced proton-transfer pathway in benzanilide ${ }^{[1]}$. The ground and excited state properties of benzanilide was analysed in various solvents using the absorption and fluorescence spectral data and also different pHs. The fluorescence behavior of benzanilide was characterized by a normal fluorescence at $345 \mathrm{~nm}$ and superposition of proton transfer fluorescence and intramolecular charge transfer fluorescence was suggested in the $480 \mathrm{~nm}$ region ${ }^{[2,3]}$. Dual emission was appeared for BA molecule in all solvents. Fast violet B is a conjugated stain with potential biochemical research applications. Fast violet B has an absorption maximum of $297 \mathrm{~nm}$ in water.

The various tautomers in organic molecules were reported such as azonium-ammonium ${ }^{[4,5]}$, azo-hydrazo ${ }^{[6]}$ and keto-enol ${ }^{[7]}$ in the presence of cyclodextrins in solution phase as well as solid phase and theoretical studies. Particularly azonium-ammonium and azo-hydrazo tautomer were investigated at the different $\mathrm{pHs}$ and also in $\beta$-cyclodextrin using the absorption and emission spectroscopic techniques.

Molecular modeling is one of the most important approaches to investigate the formation of cyclodextrin inclusion complexes, several studies using molecular dynamics, Monte Carlo Simulations, ONIOM2, DFT and mainly semiempirical methods were dedicated to the study of the nature of the interactions between cyclodextrins and the guest molecules ${ }^{[8-}$ ${ }^{12]}$. Computational study of inclusion complexes of cyclodextrins were started at 1995 by Semi-empirical methods such as AM1, PM3, PM6, PM3MM to find the electronic properties and geometry of the complexes. Ab initio calculations at the level of density functional theory had been applied in cyclodextrin chemistry ${ }^{[13]}$, were also performed to obtain the electronic structures of the inclusion complexes.

\section{Theoretical calculations}

The IUPAC name of the selected guest molecules in this manuscript are benzanilide (BA, N-benzoyl aniline, $\mathrm{N}$-phenyl benzamide) and Fast violet-B (FVB, 4-amino-5-methoxy-2-methyl benzanilide). The initial geometries of the host molecule $\beta-C D$ and tautomers of BA, FVB were constructed with Spartan 08 software. The structure of all inclusion complexes were optimized using the DFT B3LYP 3-21G method in the gas phase.

\section{Results and discussion}

Copyright (C2020 A. Antony Muthu Prabhu.

DOI: https://doi.org/10.37256/ocp.112020147

This is an open-access article distributed under a CC BY license

(Creative Commons Attribution 4.0 International License)

https://creativecommons.org/licenses/by/4.0 


\subsection{Complexation energy}

Theoretical calculations were applied to study for the inclusion complexes between organic molecules with cyclodextrins to visually make out the structure in the gas phase. Further the crystalline structure was not reported still these inclusion complexes in the solid phase with precise stoichiometric ratios (1:1 or 1:2). These stoichiometric ratios involved to find out the exact orientations with minimum complexation energy to form stable inclusion complexes. In this case also two orientations of guest molecules of amide-imino tautomers with $\beta$-CD were considered to optimize the stable inclusion complex in the gas phase. But in BA amide form it has been found the same orientation into $\beta$-CD cavity but only one different the amide group that group entering to change the interactions mainly hydrogen bond rather than van der Wall's interaction. This interaction will be played in the stability of the inclusion complex from the changing of the complexation energy. In BA molecule, the amide tautomer for orientation $\mathrm{A}$ has been found more stable inclusion complex with the -NH group inside the $\beta-\mathrm{CD}$ cavity. But the opposite results were observed for the imidol tautomer in BA molecule to forming a different arrangement with more stability of the inclusion complex.

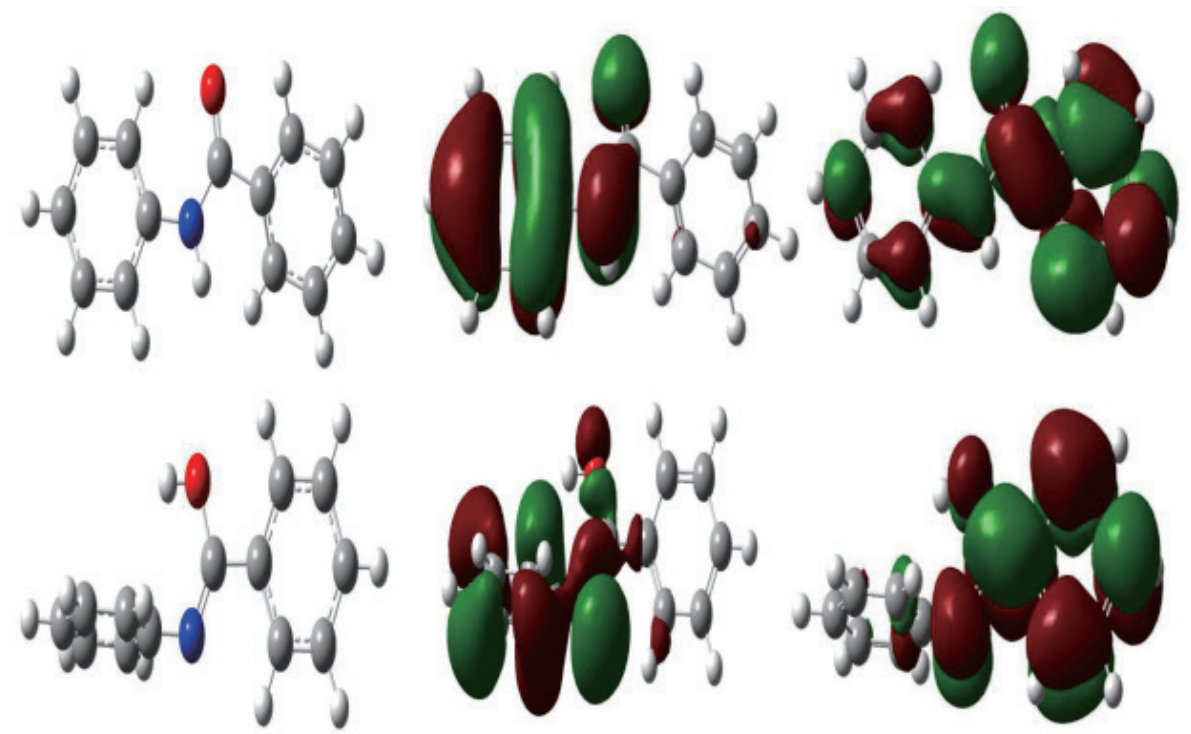

Figure 1. The optimized and HOMO, LUMO energy structure of amide-imidol tautomer of BA
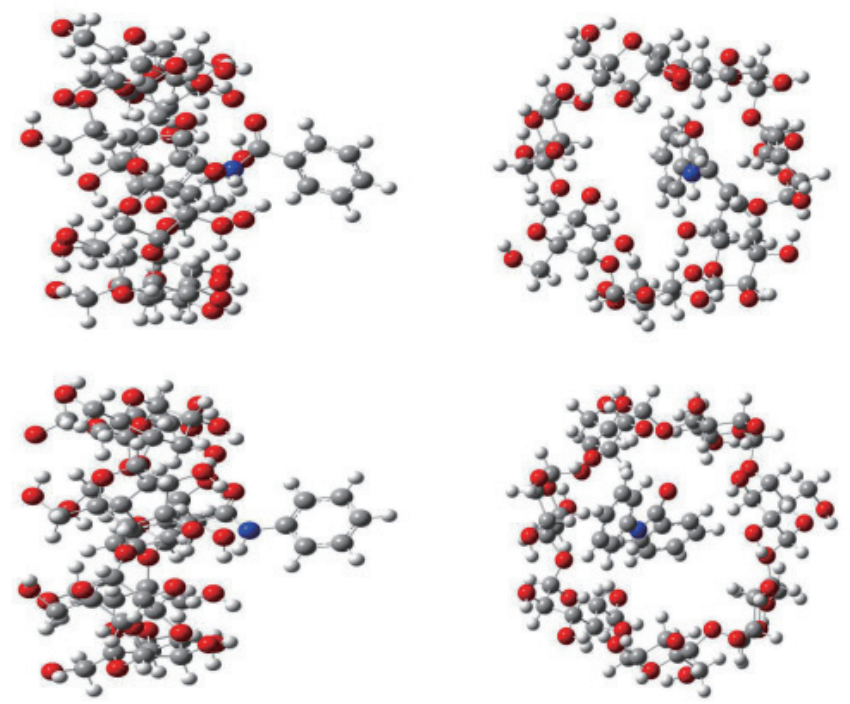

Figure 2. The optimized structure inclusion complex of amide tautomer of BA with $\beta$-CD for both orientations 

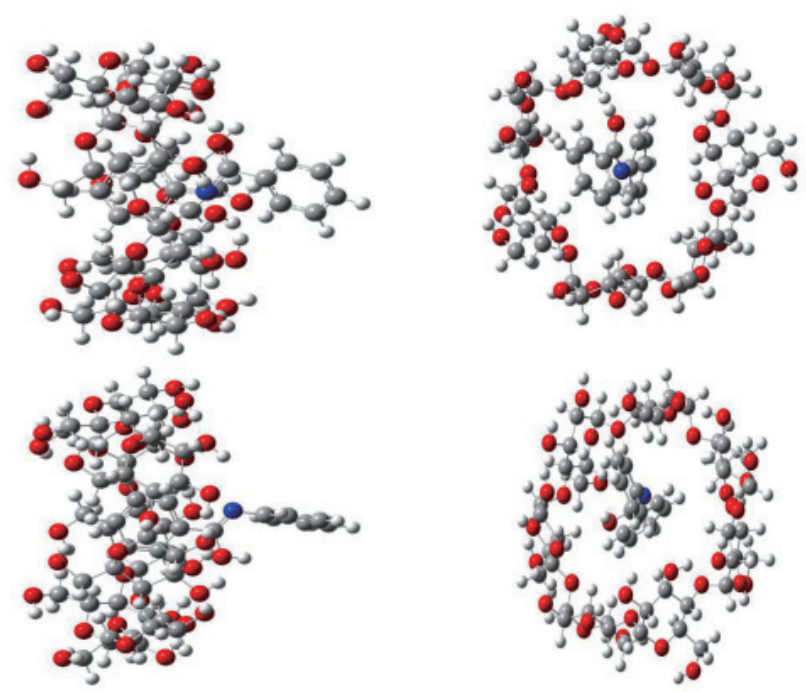

Figure 3. The optimized structure inclusion complex of imidol tautomer of BA with $\beta$-CD for both orientations
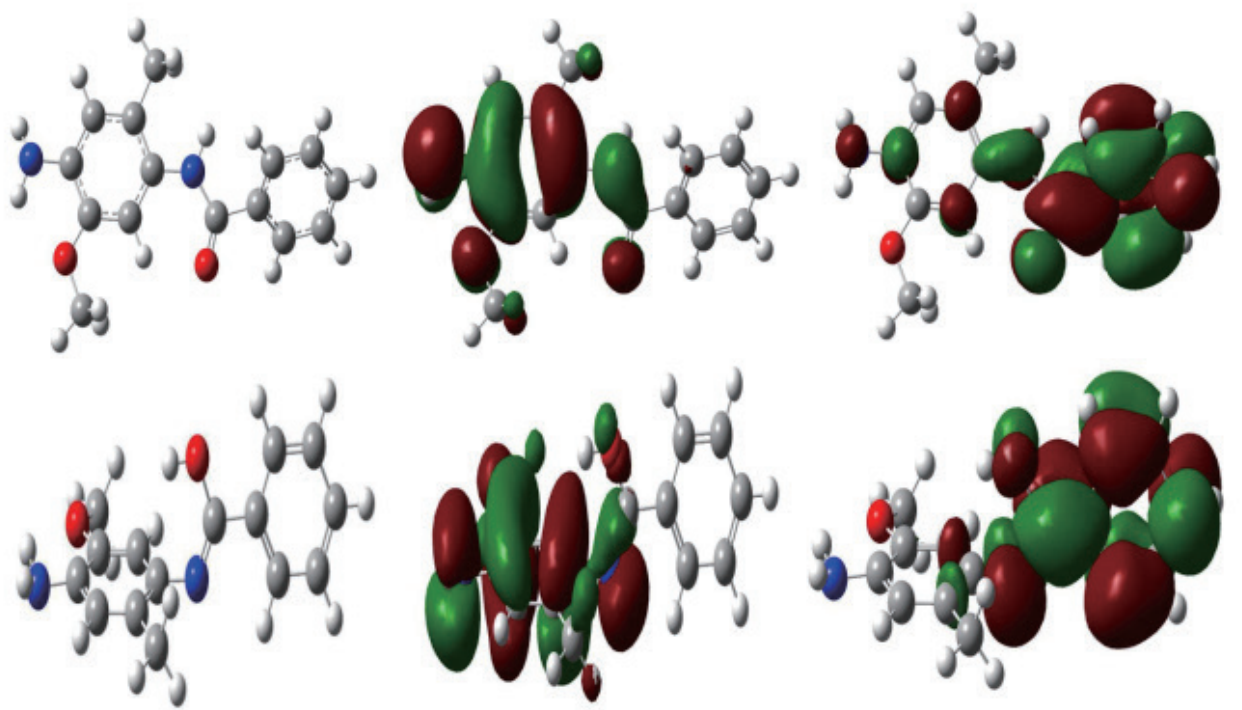

Figure 4. The optimized and HOMO, LUMO energy structure of amide-imidol tautomer of FVB 

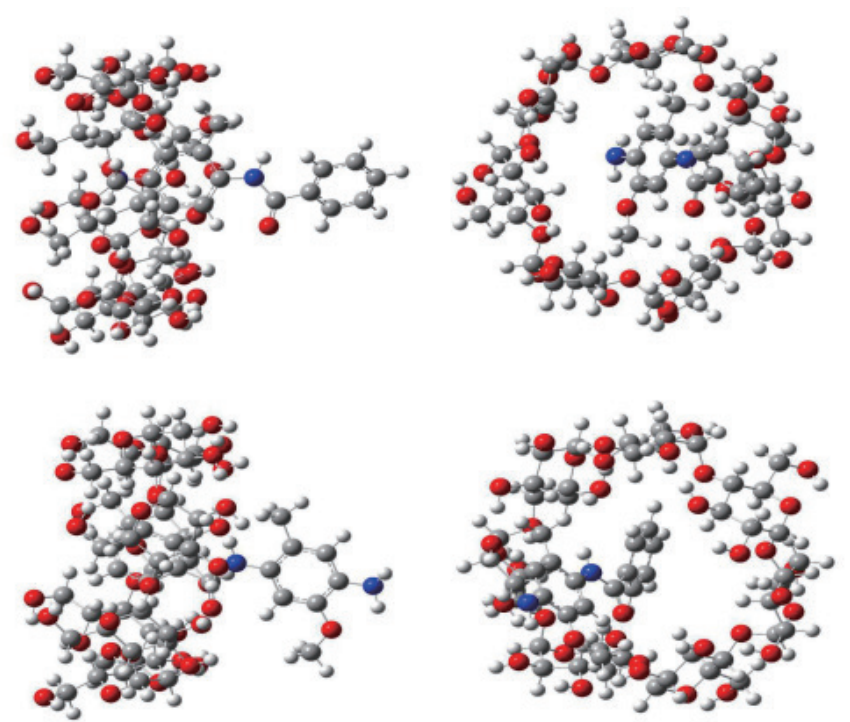

Figure 5. The optimized structure inclusion complex of amide tautomer of FVB with $\beta$-CD for both orientations
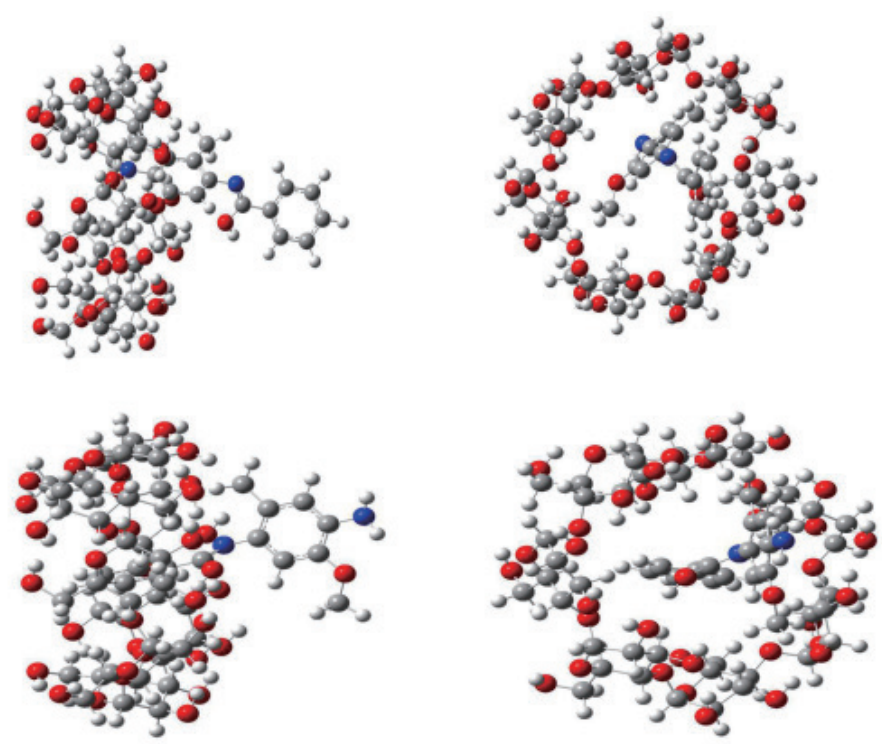

Figure 6. The optimized structure inclusion complex of imidol tautomer of FVB with $\beta$-CD for both orientations

Both orientations for BA molecule in both forms were almost similar to each other because of two sides having two benzene rings with -CO-NH group in the centre. The optimized structure of inclusion complex and HOMO, LUMO energy structure for both tautomers of guest molecules were shown in figures 1 to 6. First orientation A for FVB, the benzene ring with three substituents was encapsulated inside the $\beta$-CD cavity. The second orientation $\mathrm{B}$ has been formed with the benzene ring locating inside the $\beta-C D$ cavity.

The complexation energy $\left(\Delta \mathrm{E}_{\text {comp }}\right)$ was calculated for the minimum energy structures using the following equation:

$$
\Delta \mathrm{E}_{\text {complexation }}=\mathrm{E}_{\text {complex }}-\left(\mathrm{E}_{\mathrm{BAs}}+\mathrm{E}_{\beta-\mathrm{CD}}\right)
$$

where, $\mathrm{E}_{\mathrm{comp}}, \mathrm{E}_{\mathrm{BAs}}$ and $\mathrm{E}_{\beta-\mathrm{CD}}$ represent the total energy of the host-guest complexes, the free tautomer forms of guest molecules and the free host molecule, respectively (Tables 1 and 2). In the complex of BA- $\beta$-CD in both forms, there are no substitutions in the both aromatic rings but the complexation energy was different for the two orientations. In amide tautomer Orientation A has more stable inclusion complex $\left(-24.81 \mathrm{KJ} \mathrm{mol}^{-1}\right)$ but in imidol tautomer orientation B more stable inclusion complex $\left(-27.96 \mathrm{KJ} \mathrm{mol}^{-1}\right)$. This result indicates that the $-\mathrm{CO}-\mathrm{NH}$ - group is the determining factor of the stability for this inclusion complex ${ }^{[14]}$. Another complex FVB- $\beta-C D$ in both forms, Orientation A has more negative value $\left(-28.51 \mathrm{KJ} \mathrm{mol}^{-1}\right.$ and $\left.-29.21 \mathrm{KJ} \mathrm{mol}^{-1}\right)$ with the three substitutions in the aromatic ring locating inside the $\beta-\mathrm{CD}$ cavity. 
Table 1. Binding energies and HOMO, LUMO energy of BA before and after inclusion complexation by DFT B3LYP 3-21G method

\begin{tabular}{|c|c|c|c|c|c|c|c|}
\hline Properties & BA Amide & BA Imidol & $\beta-C D$ & BA Amide : $\boldsymbol{\beta}$-CD A & BA Amide : $\beta$-CD B & BA Imidol : $\beta$-CD A & BA Imidol : $\beta$-CD B \\
\hline $\mathrm{E}(\mathrm{kcal} / \mathrm{mol})$ & -394407.80 & -394389.48 & -2667966.44 & -3062399.05 & -3062388 & -3062348.23 & -3062383.88 \\
\hline$\triangle \mathrm{E}(\mathrm{kcal} / \mathrm{mol})$ & & & & -24.81 & -14.62 & 7.69 & -27.96 \\
\hline $\mathrm{E}_{\text {номо }}(\mathrm{eV})$ & -5.98 & -5.99 & -5.25 & -5.59 & -5.49 & -4.60 & -5.74 \\
\hline $\mathrm{E}_{\text {LUMO }}(\mathrm{eV})$ & -0.98 & -1.00 & 0.50 & -1.20 & -1.11 & -1.02 & -1.16 \\
\hline $\begin{array}{c}\mathrm{E}_{\text {Hомо }}-\mathrm{E}_{\text {LUMO }} \\
(\mathrm{eV})\end{array}$ & -4.99 & -4.99 & -5.75 & -4.38 & -4.37 & -3.57 & -4.58 \\
\hline$\mu(\mathrm{eV})$ & -3.48 & -3.49 & -3.11 & -3.28 & -3.23 & -2.79 & -3.36 \\
\hline$\chi(\mathrm{eV})$ & 3.48 & 3.49 & 3.11 & 3.28 & 3.23 & 2.79 & 3.36 \\
\hline$\eta(\mathrm{eV})$ & -2.50 & -2.49 & -3.24 & -2.39 & -2.43 & -2.48 & -2.41 \\
\hline $\mathrm{S}(\mathrm{eV})$ & -0.40 & -0.40 & -0.30 & -0.41 & -0.41 & -0.40 & -0.41 \\
\hline$\omega(\mathrm{eV})$ & -5.00 & -4.98 & -6.48 & -4.78 & -4.87 & -4.96 & -4.82 \\
\hline
\end{tabular}

Table 2. Binding energies and HOMO, LUMO energy of FVB before and after inclusion complexation by DFT B3LYP 3-21G method

\begin{tabular}{|c|c|c|c|c|c|c|}
\hline Properties & FVB Amide & FVB Imidol & FVB Amide : $\beta$-CD A & FVB Amide : $\beta$-CD B & FVB Imidol : $\beta$-CD A & FVB Imidol : $\beta$-CD B \\
\hline $\mathrm{E}(\mathrm{kcal} / \mathrm{mol})$ & -524956.42 & -524937.77 & -3192951.37 & -3192874.52 & -3192933.42 & -3192924.61 \\
\hline$\triangle \mathrm{E}(\mathrm{kcal} / \mathrm{mol})$ & & & -28.51 & 48.34 & -29.21 & -20.40 \\
\hline $\mathrm{E}_{\text {номо }}(\mathrm{eV})$ & -4.59 & -4.65 & -4.89 & -4.72 & -4.51 & -4.83 \\
\hline $\mathrm{E}_{\text {LUMO }}(\mathrm{eV})$ & -0.80 & -0.87 & -0.98 & -0.93 & -0.84 & -1.09 \\
\hline $\begin{array}{c}\mathrm{E}_{\text {HOMO }}-\mathrm{E}_{\text {LUMO }} \\
(\mathrm{eV})\end{array}$ & -3.79 & -3.77 & -3.91 & -3.79 & -3.67 & -3.73 \\
\hline$\chi(\mathrm{eV})$ & -2.78 & -2.81 & -2.93 & -2.85 & -2.74 & -2.90 \\
\hline$\mu(\mathrm{eV})$ & 2.78 & 2.81 & 2.93 & 2.85 & 2.74 & 2.90 \\
\hline$\eta(\mathrm{eV})$ & -2.59 & -2.55 & -2.50 & -2.52 & -2.57 & -2.44 \\
\hline $\mathrm{S}(\mathrm{eV})$ & -0.38 & -0.39 & -0.40 & -0.39 & -0.38 & -0.40 \\
\hline$\omega(\mathrm{eV})$ & -5.18 & -5.11 & -5.00 & -5.05 & -5.14 & -4.89 \\
\hline
\end{tabular}

\subsection{Structural parameters}

In addition to the complexation energy, the structural parameters were calculated for both forms of guest molecules. These parameters were calculated using various formulas to investigate the structural properties of the most stable inclusion complexes. The physical parameters such as electronegativity $(\chi)$, electronic chemical potential $(\mu)$, absolute hardness $(\eta)$, softness $(\sigma)$ and nucleophilicity $(\omega)$ values were determined from the HOMO as ionization energy (IE) and LUMO as electron affinity (EA) of the systems using the following expressions respectively.

$$
\begin{aligned}
& \mu=\left(E_{\text {HOMO }}+E_{\text {LUMO }}\right) / 2 \\
& \chi=-\mu=\left(E_{\text {HOMO }}+E_{\text {LUMO }}\right) / 2 \\
& \eta=\left(E_{\text {LUMO }}-E_{\text {HOMO }}\right) / 2 \\
& S=\frac{1}{2 \eta} \\
& \omega=\mu^{2} / 2 \eta
\end{aligned}
$$

$\beta$-Cyclodextrin has an internal cavity shaped like a truncated cone about $8 \AA$ deep and 6.0-6.4 $\AA$ in diameter and this cavity possesses a relatively low polarity ${ }^{[15-17]}$. These inclusion complexes do not contain any covalent bond between host and guest molecules and their stability depends on molecular size and shape complementation but also on the external medium and environmental conditions. The most important driving forces in the inclusion complexes are electrostatic, van der Waals, hydrophobic interactions, hydrogen bonding, release of conformational strain, exclusion of cavity-bound energy water and charge transfer interaction ${ }^{[18,19]}$. 


\section{Conclusion}

The amide-imidol tautomer of two guest molecules were included with $\beta$-CD to study for the structural assignments using DFT B3LYP 3-21G method in the gas phase. The amide tautomer for orientation A has more stable with -NH group inside the $\beta$-CD cavity, but in imidol tautomer for orientation the $-\mathrm{CO}$ group has been present inside the $\beta-\mathrm{CD}$ cavity.

\section{References}

[1] Guo-Ging Tang, Jean MacInnis, Michael Kasha. Proton transfer spectroscopy of Benzanilide. The Amide-imidol tautomerism. J. Am. Chem. Soc..1987; 109: 2531-2533.

[2] K. Sivakumar, T. Stalin, N. Rajendiran. Dual fluorescence of diphenyl carbazide and benzanilide: Effect of solvents and $\mathrm{pH}$ on electronic spectra. Spectrochimica Acta Part A. 2005; 62: 991-999.

[3] A. Antony Muthu Prabhu, R.K. Sankaranarayanan, S. Siva, N. Rajendiran. Unusual spectral shifts on fast violet-B and benzanilide: Effect of solvents, $\mathrm{pH}$ and $\beta$-cyclodextin. Spectrochimica Acta Part A. 2009; 74: 484-497.

[4] G. Venkatesh, A. Antony Muthu Prabhu, N. Rajendiran. Azonium-Ammonium Tautomerism and Inclusion Complexation of 1-(2,4-diamino phenylazo) Naphthalene and 4-aminoazobenzene. J Fluoresc. 2011; 21: 1485-1497.

[5] A. Antony Muthu Prabhu, V.K. Subramanian, R.K. Sankaranarayanan et al. Azonium-Ammonium Tautomerism and assembly behaviour of inclusion complexes of $\beta$-cyclodextrin with 4-amino, 2',3-dimethylazobenzene and 4-amino azobenzene. Indian Journal of Chemistry. 2010; 49A: 407-417.

[6] J. Premakumari, G. Allan Gnana Roy, A. Antony Muthu Prabhu et al. Effect of Solvents and pH on $\beta$-Cyclodextrin Inclusion Complexation of 2,4-Dihydroxyazobenzene and 4-Hydroxyazobenzene. J Solution Chem. 2011; 40: 327347.

[7] Madi Fatiha, Largate Leila, Khatmi Djamel Eddine et al, Computational investigation of enol/keto chloramphenicol with $\beta$-cyclodextrin. J Incl Phenom Macrocycl Chem. 2013; 77: 421-427.

[8] J.J.P. Stewart. Optimization of parameters for semiempirical methods V: Modification of NDDO approximations and applications to 70 elements. J. Mol. Model. 2007; 13: 1173-1214.

[9] A.D. Sayede, A. Ponchel, G. Filardo et al. Host-guest inclusion complexes between peracetylated $\beta$-cyclodextrin and diphenyl(4-phenylphenyl)phosphine: Computational studies. J. Mol. Struct. (Theochem) 2006; 777: 99-106.

[10] C. Yan, X. Li, Z. Xiu et al. Theoretical study for quercetin/ $\beta$-cyclodextrin complexes: quantum chemical calculations based on the PM3 and ONIOM2 method. J. Incl. Phenom. 2007; 58: 337-344.

[11] D. Bodgan, C. Morari. Electronic structure and driving forces in $\beta$-cyclodextrin: Diclofenac inclusion complexes. Phys. Lett. A. 2007; 366: 454-459.

[12] M. Rahim, F. Madi, L. Nouar, A. Bouhadiba, S. Haiahem, D.E. Khatmi, Y. Belhocine, Driving forces and electronic structure in $\beta$-cyclodextrin/3,3'-diaminodiphenylsulphone complex. J. Mol. Liq. 2014; 199: 501-510.

[13] L. Liu, X.X.-S. Li, T.W. Mu et al. Interplay between molecular recognition and redox properties: A theoretical study of the inclusion complexation of $\beta$-cyclodextrin with phenothiazine and its redical cation. J. Incl. Phenom. Macrocycl. Chem. 2000; 38: 199-206.

[14] Nouar Leila, Haiahem Sakina, Abdelaziz Bouhadiba et al. Theoretical study of inclusion complexation of 3-amino-5nitrobenzisothiazole with $\beta$-cyclodextrin. J. Mol. Liq. 2011; 160: 8-13.

[15] M.L. Bender, M. Komiyama. Cyclodextrin Chemistry. Springer-Verlag, New York. 1978.

[16] J. Szejtl. Cyclodextrins and Their Inclusion Complexes. Académiai Kiadô, Budapest. 1988.

[17] F. Djedaini-Pilard, B. Perly. New Trends in Cyclodextrins Derivatives. Éditions de santé, Paris. 1990.

[18] Fatiha Madi, Djameleddine Khatmi, Nabila Dhaoui et al. Molecular model of CENS piperidine $\beta$-CD inclusion complex: DFT study. C. R. Chimie. 2009; 12: 1305-1312.

[19] C. Morari, D. Bogdan, M. Bogdan. Theoretical study of the driving forces in the alpha and beta-cyclodextrin: Diclofenac inclusion complexes. Rom. J. Phys. 2005; 50: 995-1002. 